\title{
RECEIVED
}

MAR 221996

OSTI

\section{Laboratory Procedure for the Rheological Characterization of Slurry Suspensions}

C. Y.' Chang

February 1996

Prepared for

the U.S. Department of Energy

under Contract DE-AC06-76RLO 1830

Pacific Northwest National Laboratory

Richland, Washington 99352

DISTRIBUTION OF THIS DOCUMENT IS UNLIMITED 85 


\section{Laboratory Procedure for the Rheological Characterization of Slurry Suspensions}

C. Y. Chang

February 1996

Prepared for the U.S. Department of Energy under Contract DE-AC06-76RLO 1830

Pacific Northwest National Laboratory Richland, Washington 99352 


\section{DISCLAIMER}

This report was prepared as an account of work sponsored by an agency of the United States Government. Neither the United States Government nor any agency thereof, nor Battelle Memorial Institute, nor any of their employees, makes any warranty, express or implied, or assumes any legalliability or responsibility for the accuracy, completeness, or,usefulness of any information, apparatus, product, or process disclosed, or represents that its use would not infringe privately owned rights. Reference herein to any specific commercial product, process, or service by trade name, trademark, manufacturer, or otherwise does not necessarily constitute or imply its endorsement, recommendation, or favoring by the United States Government or any agency thereof, or Battelle Memorial Institute. The views and opinions of authors expressed herein do not necessarily state or reflect those of the United States Government or any agency thereof.

\section{PACIFIC NORTHWEST NATIONAL LABORATORY operated by \\ BATTELLE \\ for the \\ UNITED STATES DEPARTMENT OF ENERGY under Contract DE-AC06-76RLO 1830}

\section{Printed in the United States of America}

Available to DOE and DOE contractors from the

Office of Scientific and Technical Information, P.O. Box 62, Oak Ridge, TN 37831; prices available from (615) 576-8401.

Available to the public from the National Technical Information Service, U.S. Department of Commerce, 5285 Port Royal Rd., Springfield, VA 22161 


\section{PNL TECHNICAL PROCEDURE}

Procedure No.: ETC-001-001 Revision No.: 0 Effective Date: 5/16/95 Page 2 of 39

TITLE: LABORATORY PROCEDURE FOR THE RHEOLOGICAL CHARACTERIZATION OF SLURRY SUSPENSIONS

\subsection{PURPOSE}

This procedure provides rheology measurements that are more reliable and accurate than those described in the technical procedure PNL-(WTC-006-4). Methods are provided to measure the sweep rheogram and steady shear viscosity with concentric cylinders, to measure the yield stress directly with a shear vane, and to measure the sweep rheogram with parallel plates.

\section{$2.0 \quad$ APPLICABILITY}

This procedure provides the experimental methods for the rheological characterization of slurry suspensions. Before each test of the rheological properties of slurries, the weight percent solids, waste oxide loading ( $(\mathrm{gWO} / \mathrm{L})$, density and $\mathrm{pH}$ should be measured in accordance with PNL-(WTC-006-4).

This procedure has been prepared in accordance with MA-70 Impact Level II requirements and will be used to measure the following rheological properties:

- Taylor vortices effect

- wall slip effect

- yield stress

- plastic viscosity

- apparent viscosity

- thixotropy/rheopexy

- steady shear viscosity.

Implementation of this procedure involves the use of Haake viscometers with MV-type and FL-type sensors for rotational geometry and Q-type sensor for torsional geometry or equivalent.

\subsection{DEFINITIONS}

Taylor vortices - A secondary flow that occurs as the inner cylinder of the concentric cylinder instruments rotates. The 


\section{PNL TECHNICAL PROCEDURE}

Procedure No.: ETC-001-001 Revision Ño.: 0. Effective Date: 5/16/95 Page 3 of 39

fast-moving fluid near the inner cylinder moves outward. Since it cannot do this en masse, it circulates outward locally and thereby forms Taylor vortices. This type of turbulent flow usually causes sudden increase of shear stress in the sweep measurement.

Wall slip effect - The occurrence of a relative velocity between the fluid at the wall and the wall itself. In concentrated suspensions, wall slip is considered to occur through an "apparent slip" mechanism. A thin stratum of liquid of lower viscosity forms adjacent to the wall and may be assumed to consist of the particle-free suspending medium. Wall slip effect usually results in a measured value of shear stress lower than that of true rheological behavior of a suspension.

Yield stress - The minimum stress that must be overcome for flow to take place.

Plastic viscosity - The slope of the shear stress versus shear rate flow curve in Bingham model.

Apparent viscosity - Viscosity of a fluid defined as the shear stress divided by shear rate. Usually used for Non-Newtonian fluid whose viscosity is not a constant but depends on the shear rate. The apparent viscosity is reported for a specific shear rate.

Thixotropy/rheopexy - A change of shear stress at constant shear rate due to changes in material structures. The change in material properties may be permanent, but often the change of viscosity is temporary; the material returns to its original condition during a sufficient time free from stress. A reversible time-dependent decrease of viscosity is termed thixotropy, and a reversible timedependent increase in viscosity is called rheopexy or antithixotropy.

Steady shear viscosity - Viscosity of a fluid measured as a constant shear rate is applied and after steady state is reached.

Kinematic viscosity - Viscosity of a fluid divided by its mass density (mass per unit volume). 


\section{PNL TECHNICAL PROCEDURE}

Procedure No.: ETC-001-001 Revision No.: 0 Effective Date: 5/16/95 Page 4 of 39

\subsection{RESPONSIBLE STAEF}

Staff responsible for implementing this procedure are

- Cognizant Scientist/Engineer

- Test Operator.

\subsection{HAZARDS ASSESSMENT}

Workplace Exposure Assessment (WEA) must be completed and on file with - Laboratory Safety.

Physical Agents: Temperature of $20^{\circ}$ (Room) to $103^{\circ} \mathrm{C}$ (Boiling) used during experiments.

Chemicals: $\quad$ For this technical procedure no specific hazardous chemicals are specified. However, for a specific material used in the measurement, associated hazardous chemicals should be listed.

\subsection{HAZARD MITIGATION}

- Personnel shall read and be familiar with Workplace Exposure Assessment (WEA) before handling the materials.

- Personnel shall wear protection gloves when handling samples at high temperatures (for example, when pouring the measured materials into a beaker or a bottle).

- Personnel shall wear acid-resistant gloves for handling acids. Acid addition should be done in a vacuum hood.

\subsection{EMERGENCY RESPONSE}

A call list shall include the office and home phone numbers of the following staff members: Cognizant Scientist/Engineer, Lead Test Operator, Laboratory Monitor, Building Manager, and Line Manager. The Hanford Site emergency number (375-2400) shall be included. 


\section{PNL TECHNICAL PROCEDURE}

Procedure No.: ETC-001-001 Revision No.: 0 Effective Date: 5/16/95 Page 5 of 39

In the event of building audible alarms (e.g., fire or criticality), laboratory personnel shall follow building emergency response procedures. In the event of fire, injury, or accident, laboratory personnel shall call the PNL single-point contact at 375-2400. In the event of loss of air flow into a hood, a staff member shall close the hood sash, leave the laboratory with proper survey, and immediately notify a Radiation Protection Technologist (RPT). For laboratory audible alarms [e.g., Continuous Air Monitor (CAM) or Area Radiation Monitor (ARM)], staff shall immediately leave the laboratory and contact an RPT.

\subsection{PREREOUISITES}

Before the beginning a test or a series of tests, the following items must be addressed:

The TEST OPERATOR shall verify that all Measuring and Test equipment (M\&TE)

- are identified on the M\&TE list for the project or activity

- are calibrated and have current calibration dates.

The IEST OPERATOR shall read and be familiar with the following documents:

- this Technical Procedure

- the Haake viscometer operation manual (see references)

- all applicable Safe Operating Procedures and Job Hazard Breakdowns

- all applicable Material Safety Data Sheets.

The TEST OPERATOR shall ensure that a laboratory record book (LRB) is available for documenting the appropriate information, which includes instrument used, observations/comments, date, name of person performing test, and results (not including data acquired by data acquisition system).

\subsection{Training and Qualification}

The Cognizant Scientist/Engineer shall document training for all test operators for test apparatus operation. 


\section{PNL TECHNICAL PROCEDURE}

Procedure No.: ETC-001-001 Revision No.: 0 Effective Date: 5/16/95 Page 6 of 39

\subsection{Recording and Reporting of Data}

All data, including figures of rheogram and data acquired by data acquisition systems, in the process of carrying out this procedure shall be recorded in the LRB or kept in the associated project file.

\subsection{Disposition of Samples}

On completion of the test, the Test Operator shall label the slurry sample for other tests or archiving or dispose of the slurry according to approved safety and waste-management procedures. The Test Operator shall note disposition of the sample in the LRB.

\subsection{PRECAUTIONS AND LIMTTATIONS}

\subsection{Personal Protective Equipment}

Personnel shall wear safety glasses for routine laboratory work and use chemical splash goggles and/or face shield when using concentrated acids and bases. Laboratory coats and vinyl chemical resistant gloves shall be used for routine laboratory work.

\subsection{Material Safety Data Sheet (MSDS)}

MSDSs shall be maintained in the laboratory and be accessible to the staff. Staff are required to read MSDSs before working with hazardous chemicals.

\subsection{EOUIPMENT DESCRIPTION}

The equipment used in this procedure are (1) a Haake rotational viscometer with a coaxial cylinder sensor system (MV sensors) and (2) a bladed vane (FL sensors) and a Haake torsional viscometer with a parallel plate sensor system $(Q$ sensors). (See Figure 10.0.1.) The apparatus includes

- $\ddot{R}$ otovisco RV20

- measuring systems $M$ (for MV and FL sensors)

- measuring systems CV20 (for Q sensors)

- temperature-controlled water bath

- data acquisition system 
PNL TECHNICAL PROCEDURE

Procedure No.: ETC-001-001 Revision No.: 0 Effective Date: 5/16/95 Page 7 of 39

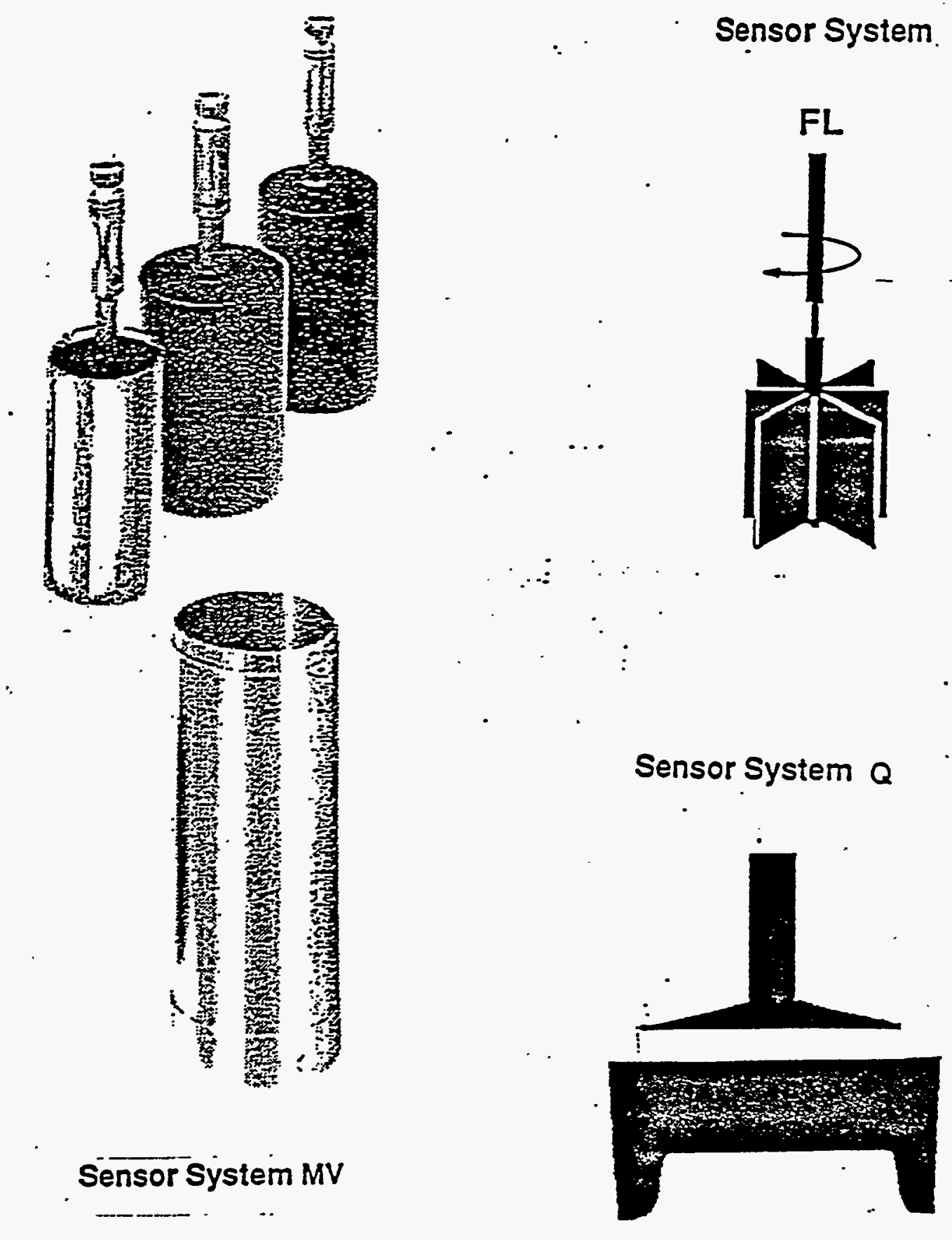

Figure 10.0.1 Different types of sensors used for the rheological measurement. 


\section{PNL TECHNICAL PROCEDURE}

Procedure No.: ETC-001-001 Revision No.: 0 Effective Date: 5/16/95 Page 8 of 39

\subsection{QUALITY CONTROL}

Calibration checks shall be performed at least once every two months, or whenever the viscometer is moved. The operator performing the calibration should record the date, name, and a summary of the calibration results in the calibration notebook located in the laboratory. Every operator shall check the calibration notebook before doing the measurement. The calibration check consists of using a viscosity standard (for example, Cannon S-series standard oil) with known liquid viscosity for the following measurement:

- Consult with cognizant scientist/engineer about the suitable type of sensor and viscosity standard for the measurement.

- Follow procedure 12.1A for Couette viscometer or 12.1D for parallel plate viscometer and calculate the viscosity (the slope of shear stress - versus shear rate curve, see Figure 11.0.1).

- Compare the results between plastic viscosity and the given viscosity value from the viscosity standard. If the values are consistent $( \pm 5 \%)$, the calibration is done. Otherwise, consult with cognizant scientist/engineer for possible errors.

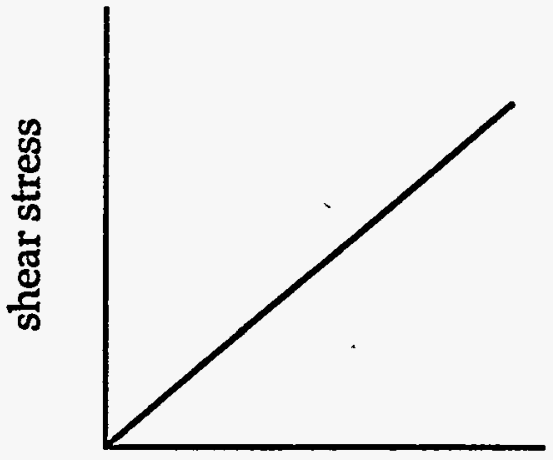

shear rate

Figure 11.0.1 The viscosity of a Newtonian fluid is equal to the slope of its shear stress versus shear-rate curve. 


\section{PNL TECHNICAL PROCEDURE}

Procedure No.: ETC-001-001 Revision No.: 0 Effective Date: 5/16/95 Page 9 of 39

\subsection{WORK INSTRUCTIONS}

The operator shall follow procedure WTC-006-4 to measure wt\% solids, $\mathrm{gWO} / \mathrm{L}$, density, and $\mathrm{pH}$ and consult with cognizant scientist/engineer for the particle size distribution of the sample and test temperature before using this procedure for the rheological measurement. A flowsheet for the overall procedure is given in Figure 12.0.1. The methods of rheological measurement are detailed in $12.1 \mathrm{~A}$ for sweep rheogram measurement with concentric cylinders, 12.1B for yield stress measurement with bladed vane, $12.1 \mathrm{C}$ for steady shear measurement with concentric cylinders, 12.1D for sweep rheogram measurement with parallel plates, and 12.2A for the application of laboratory-scale data to estimate the pressure drop in large-scale pipe flow.

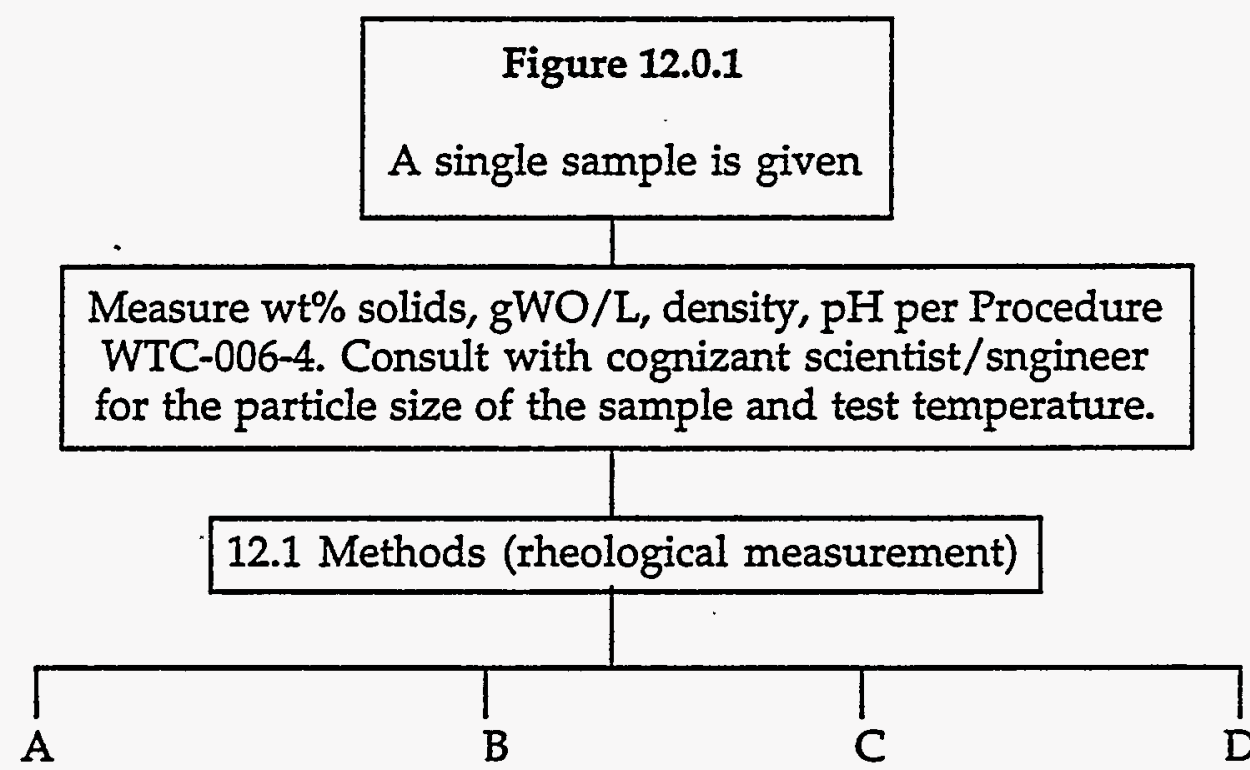

Sweep rheogram (concentric cylinders)

\section{Shear vane}

Steady shear (concentric cylinders)
Sweep rheogram (parallel plates)

\subsection{Applications}

A

Pressure drop $(\Delta \mathrm{P})$ estimation for pipe flow 


\section{PNL TECHNICAL PROCEDURE}

Procedure No.: ETC-001-001 Revision No.: 0 Effective Date: 5/16/95 Page 10 of 39

\subsection{Methods}

A. Sweep rheogram (concentric cylinders)

1. The yield stress, plastic viscosity, apparent viscosity, and qualitative thixotropic/rheopectic behavior of slurries can be measured with concentric cylinders (see Figure 12.1A on page 16).

2. Select an appropriate sensor for measurement based on viscosity ranges and particle sizes. The measuring range for a specific MV-type sensor is shown in Figure 12.1A.1 and the gap size used should be 3 times larger than the maximum particle size. For example, use Haake MV2 sensor for slurry maximum particle size $<900 \mu \mathrm{m}$, and plastic viscosity $>15 \mathrm{cp}$ and $<10^{7} \mathrm{cp}$.

- If maximum particle size $>900 \mu \mathrm{m}$, use Haake MV3 sensor.

- If plastic viscosity $<15 \mathrm{cp}$, use Haake MV1 sensor. .

- If plastic viscosity $>10^{7} \mathrm{cp}$, use an alternative method, such as parallel plate geometry which may be used for highly viscous materials.

- If plastic viscosity $<15 \mathrm{cp}$ and maximum particle size $>900 \mu \mathrm{m}$ (materials with low viscosity and large particle sizes), methods development is needed.

A trial and error approach may be required to determine which sensor is appropriate for use.

3. Shake or stir the sample to make sure that it has been homogenized. Add sample to the appropriate level. For the Haake MV2 sensor this is the second lowest ring mark in the cup. Three samples are to be used.

4. Remove excess sample with a suitable syringe. (Note: if not enough sample is loaded, the measured shear stress value will be less than the correct value.)

5. Avoid liquid loss during the experiment, which may cause an increase in measured shear stress, by adding a thin layer of mineral oil over the sample. Usually, this is necessary for measurements performed at high temperature (the temperature depends on the composition of the slurries). However, after mineral oil is used, the sample should be disposed of and not be used again. 


\section{PNL TECHNICAL PROCEDURE}

Procedure No.: ETC-001-001 Revision No.: 0 Effective Date: 5/16/95 Page 11 of 39

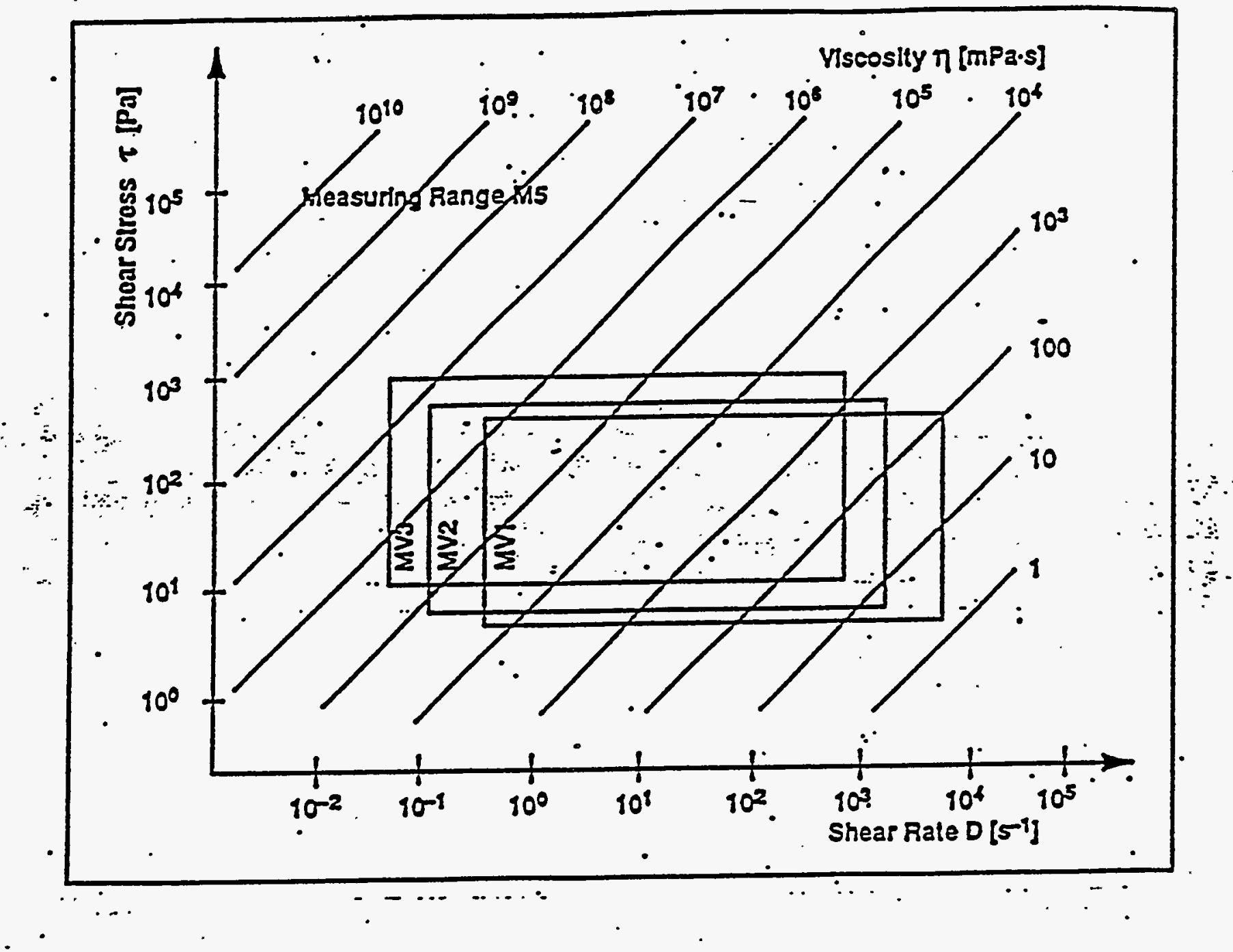

Figure 12.1A.1 The measuring range for a specific MV-type sensor. 


\section{PNL TECHNICAL PROCEDURE}

Procedure No.: ETC-001-001 Revision No.: 0 Effective Date: 5/16/95 Page 12 of 39

6. Set sweep time:

$0-451 \mathrm{~s}^{-1}: 2$ minutes, then $451-0 \mathrm{~s}^{-1}: 2$ minutes. (Note: increasing the shear time for the period of 0 to $451 \mathrm{~s}^{-1}$ can reduce the thixotropic/rheopectic phenomenon, however, the original material microstructure can also be disturbed during a longer preshear time.) Here, $451 \mathrm{~s}^{-1}$ is the maximum shear rate range for MV2 sensor. Due to the sensitivity of the slurry to shear history, consult with cognizant scientist/engineer if a longer period of shear time is required.

7. Check if sensor size is correct, i.e., if the values of shear stress for shear rate between 0 and $451 \mathrm{~s}^{-1}$ are in the valid range as shown in Figure 12.1A.1.

- If no, consult with cognizant scientist/engineer for a proper type of sensor.

- If yes, go to next step.

8. Measure shear stress versus shear rate (three fresh samples total, use new sample after each measurement). (Note: fresh samples must be loaded for each measurement because the slurries may be sensitive to the shear history.)

9. Use both upper and lower curves (if thixotropy/rheopexy is observed) for analysis. The upper curve approximates the starting flow in pipe (where the fluid was initially undisturbed), while the lower curve approximates the sheared flow in pipe (where the fluid has been deformed as the time progresses).

10. Check if each upper and lower flow curve is repeatable $( \pm 5 \%)$ for three runs.

- If flow curves are not consistent, consult with cognizant scientist/engineer before continuing the work.

- If flow curves are consistent, go to next step.

11. Check flow curves for Taylor vortices, i.e., a sudden shear-stress increase on the flow curve (see Figure 12.1.2). 


\section{PNL TECHINICAL PROCEDURE}

Procedure No.: ETC-001-001 Revision No.: 0 Effective Date: 5/16/95 Page 13 of 39

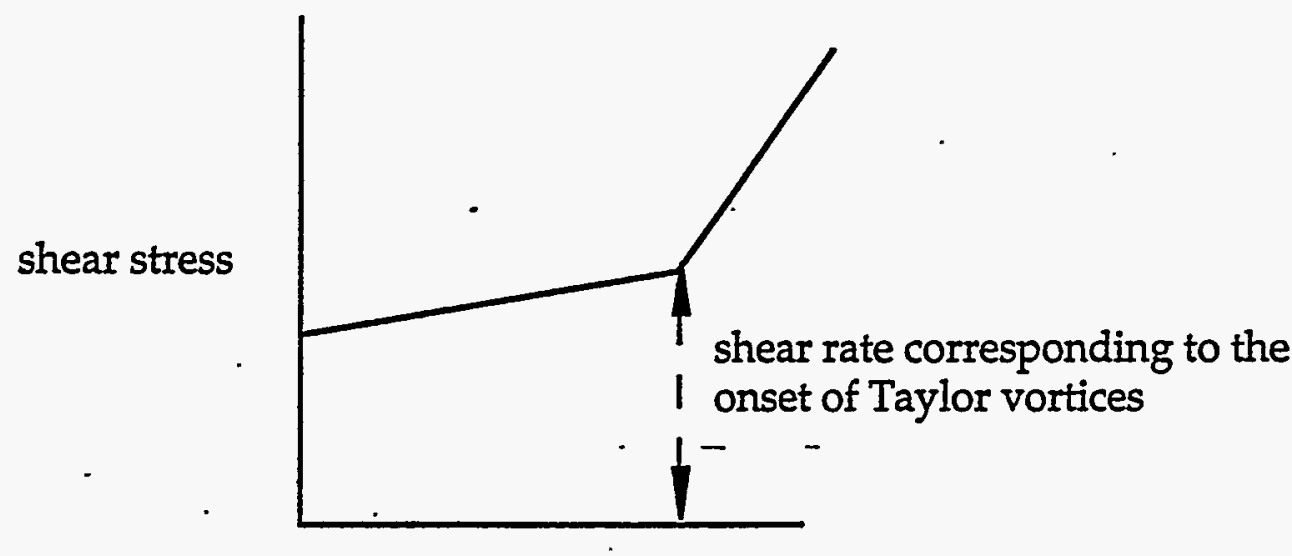

shear rate

Figure 12.1.2 The sudden shear stress increase on the flow curve indicates the existence of Taylor vortices.

- If no, go to next step.

- If yes, estimate shear rate where onset of Taylor vortices is predicted.

Taylor vortices are predicted at:

$$
\operatorname{Re}>41.3\left\{\mathrm{R}_{2} /\left(\mathrm{R}_{2}-\mathrm{R}_{1}\right)\right\}^{1 / 2},
$$

where:

$$
\operatorname{Re}=\dot{\gamma}\left(R_{2}-R_{1}\right)^{2} \rho / \mu \text {. }
$$

$R_{1}[\mathrm{~m}]$ and $R_{2}[\mathrm{~m}]$ are the radius of inner and outer cylinder, respectively; $\dot{\gamma}\left[\mathrm{s}^{-1}\right]$ is the shear rate; $\rho\left[\mathrm{g} / \mathrm{m}^{3}\right]$ is the density of fluid; and $\mu[\mathrm{Pa} \cdot \mathrm{s}]$ is the viscosity (or apparent viscosity for non-Newtonian fluids) obtained from the measurement.

Compare the predicted value and the experimental value for consistency $( \pm 10 \%)$.

- If no, consult with cognizant scientist/engineer before continuing the work.

- If yes, discard data beyond the point where Taylor vortices occur. 


\section{PNL TECHNICAL PROCEDURE}

Procedure No.: ETC-001-001 Revision No.: 0 Effective Date: 5/16/95 Page 14 of 39

(Note: use of an alternative sensor with smaller gap size may reduce Taylor vortices, but increase wall-slip effect.)

12. Identify if wall-slip corrections are required. Repeat steps 3-11 with a Haake MV1 sensor (shear rate range $0-1160 \mathrm{~s}^{-1}$ ), and discard invalid data, if necessary, for Taylor vortices. (Note: the formulas that will be used to correct wall slip are

- only valid for narrow gap sensors, i.e., $R_{1} / R_{2}$ should be larger than 0.8 ; therefore, MV3 sensor which has $R_{1} / R_{2}=0.72$ can not be used.) For MV1 and MV2 sensors, the values of $R_{1} / R_{2}$ are 0.95 and 0.88 , respectively.

13. Check if wall-slip effect exists. (Note: if there is no wall slip, the flow curves using MV1 and MV2 sensors should be the same $[ \pm 5 \%]$ )

- If no, go to next step.

- If yes, correct wall slip and obtain correct flow curve by use of the following formulas (Kiljanski 1989).

- Obtain the shear rate $\dot{\gamma}_{\mathrm{m} 1}^{\prime}\left[\mathrm{s}^{-1}\right]$ and $\dot{\gamma}_{\mathrm{m} 2}^{\prime}\left[\mathrm{s}^{-1}\right]$ from MV1 and MV2 sensors for a specific shear stress $\tau_{m}[\mathrm{~Pa}]$ (recommend minimum of $10 \tau_{m}$ values)

- Calculate u $[\mathrm{m} / \mathrm{s}]$ for each $\tau_{\mathrm{m}}[\mathrm{Pa}]$

$$
u=\frac{\dot{\gamma}_{m 1}^{\prime}-\dot{\gamma}_{m 2}^{\prime}}{\left(1 / b_{1}\right)-\left(1 / b_{2}\right)}
$$

where

$$
b=\frac{R_{i} R_{a} \ln \left(R_{a} / R_{i}\right)}{R_{i}+R_{a}}
$$

$R_{\mathrm{l}}[\mathrm{m}]$ and $R_{\mathrm{a}}[\mathrm{m}]$ are the radii of ininer and outer cylinders.

- Calculate $\dot{\gamma}_{\mathrm{ml}}\left[\mathrm{s}^{-1}\right]$ for each $\tau_{\mathrm{m}}[\mathrm{Pa}]$

$$
\dot{\gamma}_{m 1}=\ddot{\gamma}_{m 1}-\frac{u_{1}}{b_{1}}
$$




\section{PNL TECHNICAL PROCEDURE}

Procedure No.: ETC-001-001 Revision No:: 0 Effective Date: 5/16/95 Page 15 of 39

- Plot out $\tau_{m}[\mathrm{~Pa}]$ versus $\dot{\gamma}_{\mathrm{ml}}\left[\mathrm{s}^{-1}\right]$

14. Use curve-fitting software on corrected flow curve.

15. Select best model based on regression for non-Newtonian Fluid (Bingham, H. Bulkley, Casson, etc.). If fluid is Newtonian, $\tau=\eta \dot{\gamma}$ where $\tau[\mathrm{Pa}]$ is the shear stress, $\eta$ [Pa.s] the Newtonian viscosity, and $\dot{\gamma}\left[s^{-1}\right]$ the shear rate.

- Bingham Model: $\tau=\tau_{0}^{\mathrm{B}}+\eta_{\mathrm{p}} \dot{\gamma}$ where $\tau[\mathrm{Pa}]$ is the shear stress, $\tau_{0}^{\mathrm{B}}[\mathrm{Pa}]$ the Bingham yield stress, $\eta_{\mathrm{p}}[\mathrm{Pa} \cdot \mathrm{s}]$ the plastic viscosity, and $\dot{\gamma}\left[\mathrm{s}^{-1}\right]$ the shear rate.

- Herschel-Bulkley Model: $\tau=\tau_{0}^{\mathrm{H}}+k \dot{\gamma}^{\mathrm{n}}$ where $\tau[\mathrm{Pa}]$ is the shear stress, $\tau_{0}^{\mathrm{H}}[\mathrm{Pa}]$ the yield stress, $k$ and $n$ the parameters, and $\dot{\gamma}\left[\mathrm{s}^{-1}\right]$ the shear rate.

- Casson Model: $\tau^{\frac{1}{2}}=\left(\tau_{0}^{c}\right)^{\frac{1}{2}}+\left(\eta_{c} \dot{\gamma}\right)^{\frac{1}{2}}$ where $\tau[\mathrm{Pa}]$ is the shear stress, $\tau_{0}^{c}[\mathrm{~Pa}]$ the Casson yield stress, $\eta_{\mathrm{c}}[\mathrm{Pa} \cdot \mathrm{s}]$ the consistency parameter, and $\dot{\gamma}\left[\mathrm{s}^{-1}\right]$ the shear rate.

(Note: if the material has no yield stress, $\tau_{0}^{\mathrm{B}}, \tau_{0}^{\mathrm{H}}$, and $\tau_{0}^{\mathrm{c}}$ should be zero.)

16. Obtain the following parameters from each model: (This is for the pressure drop estimate in pipe flow, see Section 12.2 on page 35 )

- Bingham Model: the Bingham yield stress, $\tau_{0}^{\mathrm{B}}$, and the plastic viscosity, $\eta_{\mathrm{p}}$.

- Herschel-Bulkley Model: the yield stress, $\tau_{0}^{\mathrm{H}}$, and the parameters, $k$ and $n$.

- Casson Model: the Casson yield stress, $\tau_{0}^{c}$ and the consistency parameter, $\eta_{c}$.

17. Determine apparent viscosity by dividing the corrected shear stress by a specific shear rate. For example, the apparent viscosity for a shear rate $\dot{\gamma}$ with shear stress $\tau$ is $\tau / \dot{\gamma}$.

18. Determine thixotropic/rheopectic behavior by measuring the area between the "up" and "down" curves of the corrected rheogram (Mewis 1979). 
PNL TECHNICAL PROCEDURE

Procedure No.: ETC-001-001 Revision No.: 0 Effective Date: 5/16/95 Page 16 of 39

Figure 12.1A

Sweep rheogram (concentric cylinders)

A1

A2

Sweep rheogram

- yield stress

- plastic viscosity

- apparent viscosity

- thixotropy/rheopexy

Use MV2 sensor for particle sizes

$<900 \mu \mathrm{m}$ and slurry viscosity

$>15 \mathrm{cp}$ and $<10^{7} \mathrm{cp}$

A3

Add sample to the appropriate level

A4

( 3 samples will be used)

Remove excess sampla

A5

Avoid liquid loss

A6

Set sweep time: $0-451 \mathrm{~s}^{-1}: 2$ minutes, $451-0 s^{-1}: 2$ minutes

A7

Is the sensor size correct? (i.e., shear stress in the valid range for shear rate between $0-451 \mathrm{~s}^{-1}$ as shown in Figure 12.1A.1)

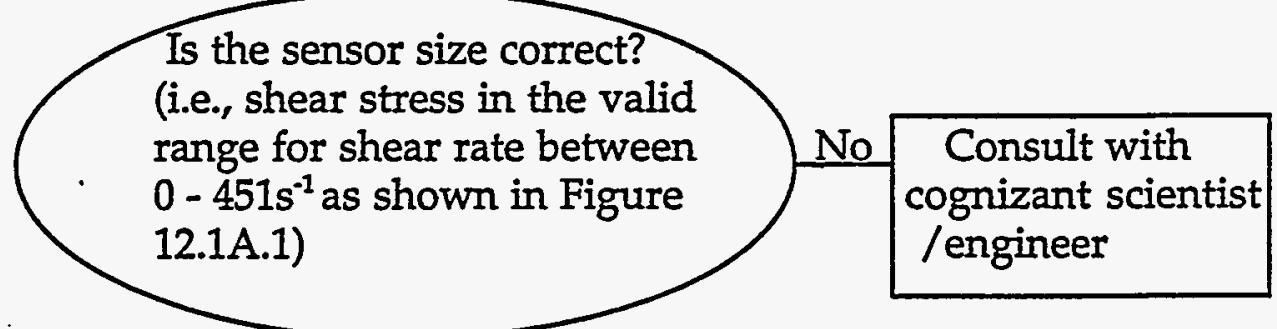

Measure shear stress versus shear rate (3 fresh samples total) 


\section{PNL TECHINICAL PROCEDURE}

Procedure No.: ETC-001-001 Revision No.: 0 Effective Date: 5/16/95 Page 17 of 39

A9

Use both upper and lower curves (which approximate the undisturbed and sheared

flows in pipe) for analysis

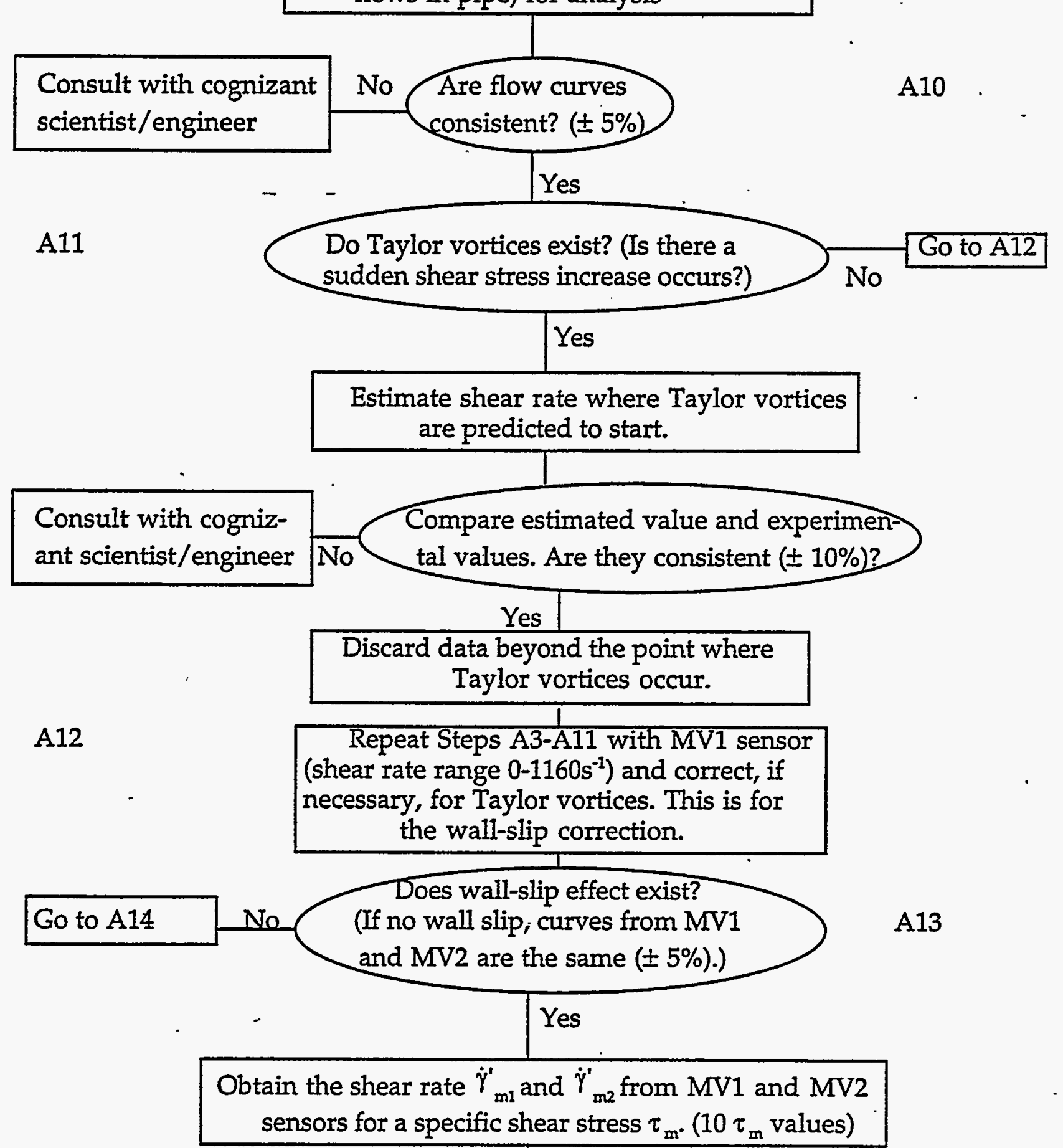


PNL TECHNICAL PROCEDURE

Procedure No.: ETC-001-001 Revision No:: 0 Effective Date: 5/16/95 Page 18 of 39

A14

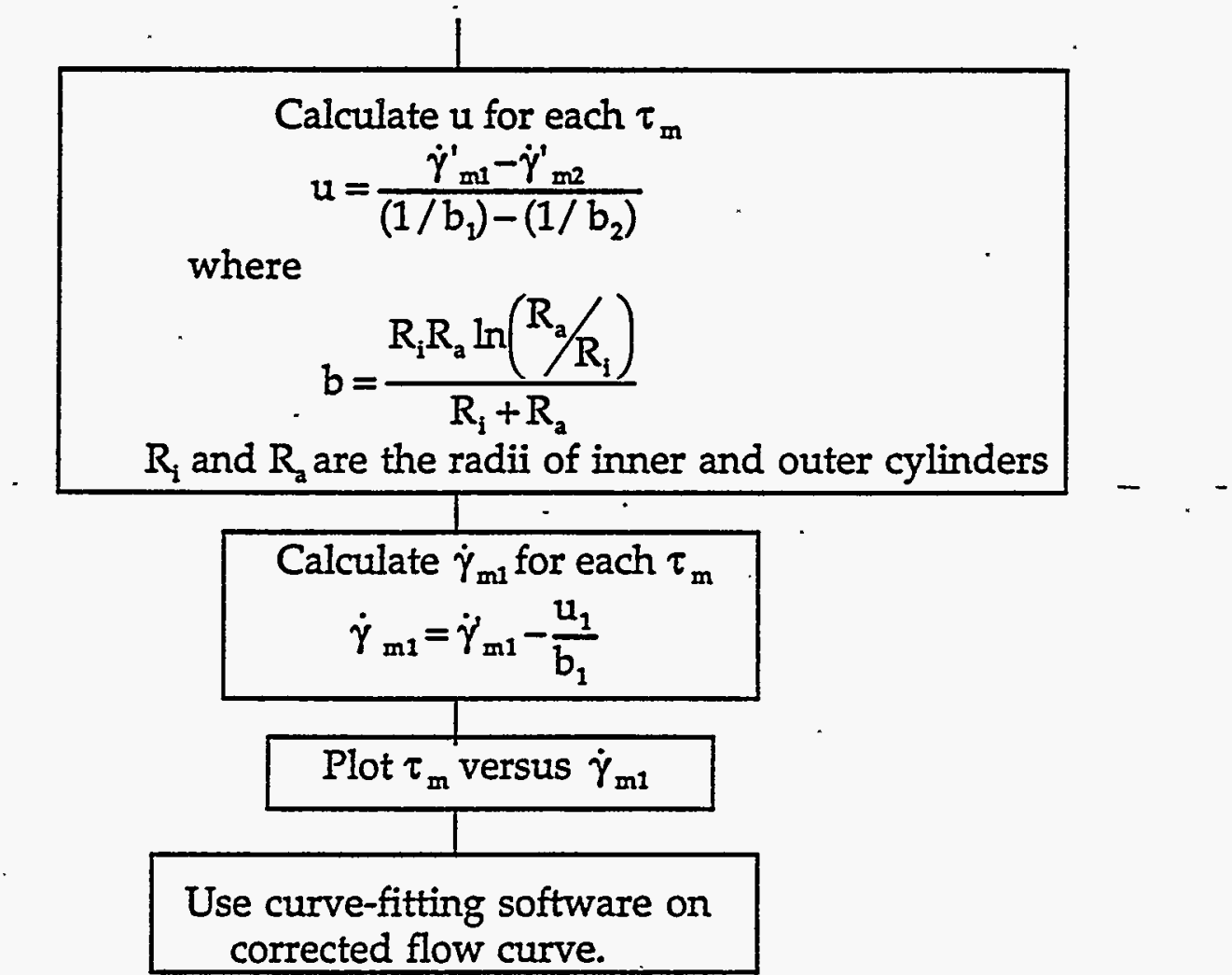

A15

Select best model based on regression (Bingham, H.Bulkley, Casson, etc.).

Obtain the following parameters from each model:

- Bingham model: the Bingham yield stress, $\tau_{0}^{\mathrm{B}}$, and the plastic viscosity, $\eta_{\mathrm{p}}$.

- Herschel-Bulkley Model: the yield stress, $\tau_{0}^{\mathrm{H}}$, and the parameters, $k$ and $n$.

- Casson Model: the Casson yield stress, $\tau_{0}^{\mathrm{c}}$ and the consistency parameter, $\eta_{\text {. }}$.

A17 Determine apparent viscosity by dividing the corrected shear stress by a specific shear rate.
Determine thixotropy/rheopexy behavior by measuring the area between the "up" and "down" curves of the corrected rheogram. 


\section{PNL TECHNICAL PROCEDURE}

Procedure No.: ETC-001-001 Revision No.: 0 Effective Date: 5/16/95 Page 19 of 39

\section{B. Shear vane}

1. The yield stress is measured directly with a bladed vane (see Figure 12.1B on page 21). For concentric-cylinder and parallel-plate geometries, the yield stress can only be obtained indirectly, and sometimes tedious corrections may need to be made due to wall-slip effect.

2. Select sensor for measurement. Use FL10 sensor (A-[the shear stress] factor=2.7, $M$-[the shear rate] factor $=1.05$ ) from Haake for slurry plastic viscosity $100-10^{4} \mathrm{cp}$; FL100 sensor (A-factor $=28.2, \mathrm{M}$-factor $=1.05$ ) for slurry plastic viscosity $10^{3}-10^{5} \mathrm{cp}$; and FL1000 sensor (A-factor=263, M-factor $=1.05$ ) for slurry plastic viscosity $10^{4}-10^{6}$ cp. (Note: Step 2-Step 8 are for a constant shear rate viscometer. If a constant stress viscometer is used, the same technique can be applied; go to Step 9.) A trial and error approach may be required to determine which sensor is . appropriate for use.

3. Shake or stir the sample to make sure that it has been homogenized. Pour slurry sample into a beaker. Three samples are to be used.

4. Place a jack beneath the beaker. Slowly raise the jack and let the shear vane insert into the beaker and try not to disturb the sample. The diameter of beaker / diameter of vane should be $>2.0$, top of vane to air surface / diameter of vane . should be $>1.0$, and bottom of vane to bottom of beaker / diameter of vane should be $>0.5$ to avoid wall effects.

5. Measure shear stress versus time at different low rotational speeds $(0.1-5 \mathrm{rpm})$. Stir sample well (to avoid shear history effect) and wait for a couple of minutes (to avoid thixotropy/rheopexy effect due to stirring) before each test.

6. Check if the maximum values of shear stress are the same $( \pm 5 \%)$ at different low rotational speeds.

- If no, consult with cognizant scientist/engineer before continuing the work.

- If yes, average the maximum values of shear stress (the average value $=\tau_{1}[\mathrm{~Pa}]$ ) and go to next step.

7. Repeat Steps 3 through 6 with the other two fresh samples (three fresh samples total) and obtain the other two average values $\tau_{2}[\mathrm{~Pa}]$ and $\tau_{3}[\mathrm{~Pa}]$. 


\section{PNL TECHNICAL PROCEDURE}

Procedure No.: ETC-001-001 Revision No.: 0 Effective Date: 5/16/95 Page 20 of 39

8. Check if $\tau_{1}, \tau_{2}$ and $\tau_{3}$ are the same ( $\pm 5 \%$ ) for the three different runs.

- If no, consult with cognizant scientist/engineer before continuing the work.

- If yes, the average value of $\tau_{1}, \tau_{2}$ and $\tau_{3}$ is the yield stress of the material.

9. The following steps of yield stress measurement are for a constant stress viscometer:

9.1 Repeat Step 3 and Step 4, Shear vane, above.

9.2 Measure torque versus time at different low constant stresses. Stir sample and wait for a couple of minutes before each test.

9.3 Check if the maximum values of torque are the same $( \pm 5 \%)$ at different low applied stresses.

- If no, consult with cognizant scientist/engineer before continuing the work.

- If yes, average the maximum values of shear stress (the average value $=\tau_{4}$ ) and go to next step.

9.4 Repeat Step 9.1-Step 9.3 above with the other two fresh samples (three fresh samples total) and obtain the other two average values $\tau_{4}$ and $\tau_{5}$.

9.5 Check if $\tau_{4 r} \tau_{5}$ and $\tau_{6}$ are the same ( $\pm 5 \%$ ) for the three different runs.

- If no, consult with cognizant scientist/engineer before continuing the work.

- If yes, average the values of $\tau_{1}, \tau_{2}$ and $\tau_{3}$ (the average value $=T_{m}[N \cdot m]$ ) and go to next step.

9.6 Calculate yield stress using the following formula (Dzuy and Boger 1983):

$$
\tau_{y}=\frac{T_{m}}{\left[\frac{\pi D^{2}}{2}\left(\frac{H}{D}+\frac{1}{3}\right)\right]}
$$

where $\tau_{\mathrm{y}}[\mathrm{Pa}]$ is the yield stress, $\mathrm{T}_{\mathrm{m}}[\mathrm{N} \cdot \mathrm{m}]$ the torque obtained in Step 9.5, $\mathrm{D}[\mathrm{m}]$ the diameter of the vane, and $\mathrm{H}[\mathrm{m}]$ the height of the vane. 


\section{PNL TECHNICAL PROCCEDURE}

Procedure No.: ETC-001-001 Revision No.: 0 Effective Date: 5/16/95 Page 21 of 39

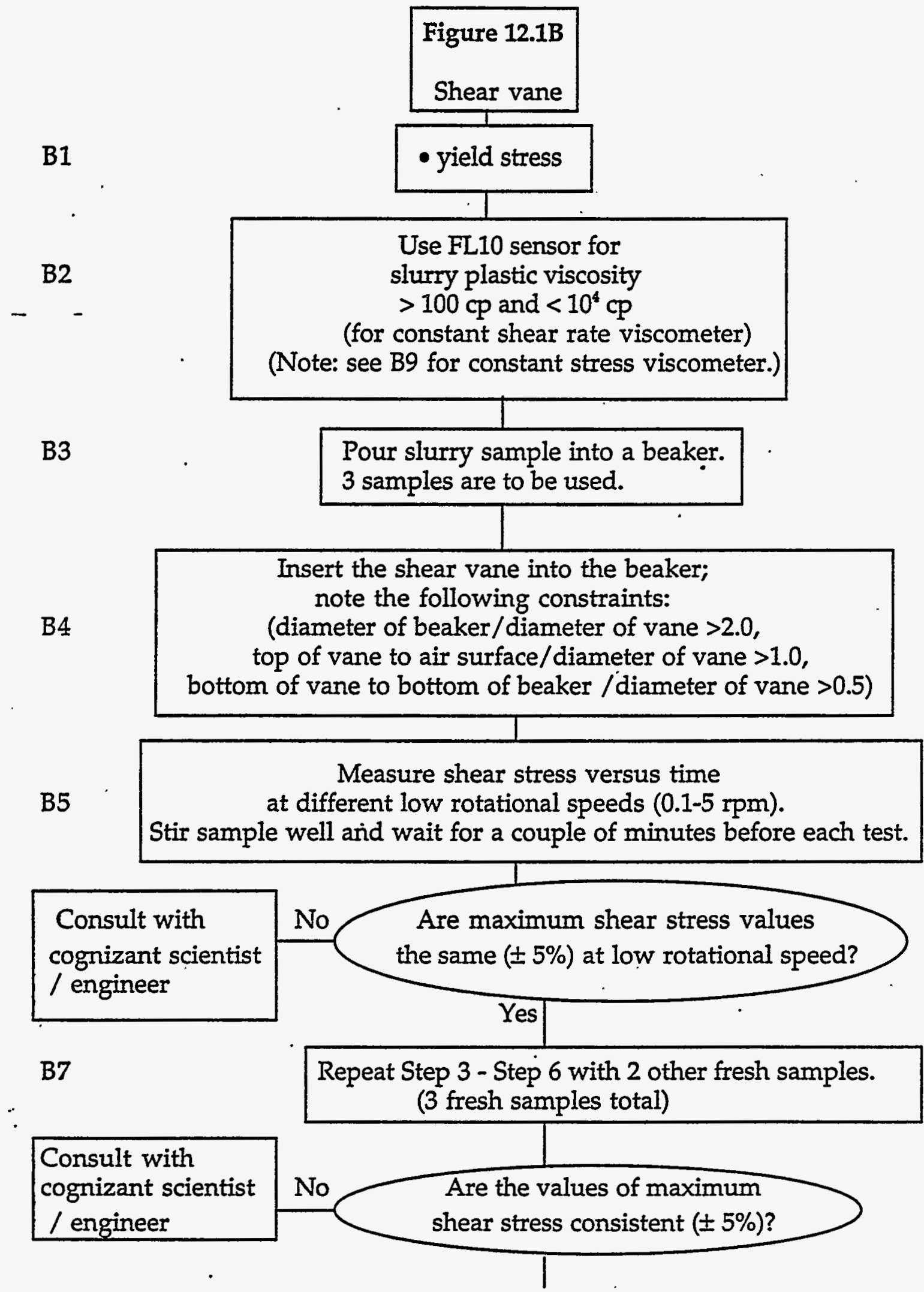




\section{PNL TECHNICAL PROCEDURE}

Procedure No.: ETC-001-001 Revision No.: 0 Effective Date: 5/16/95 Page 22 of 39

Yes

The measured value is the yield stress of the material.

B9

Yield stress measurement for a constant stress viscometer

B9.1

Repeat Steps 3 and 4.

B9.2

Measure torque versus time at different low constant stresses. Stir sample well and wait for a couple of minutes before each test.

\section{Consult with / engineer}

B9.4

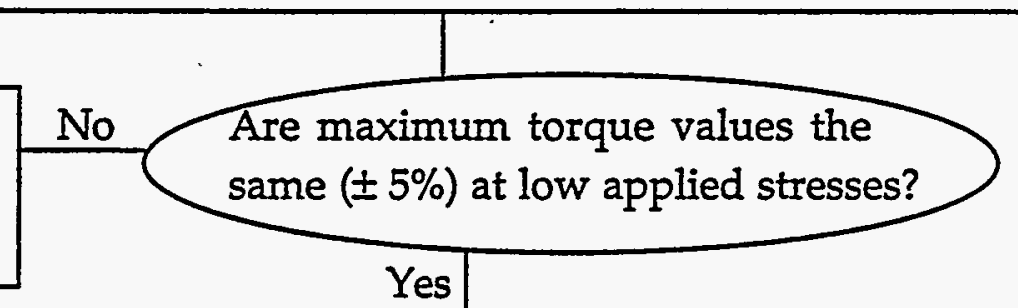

Consult with cognizant scientist / engineer

B9.6

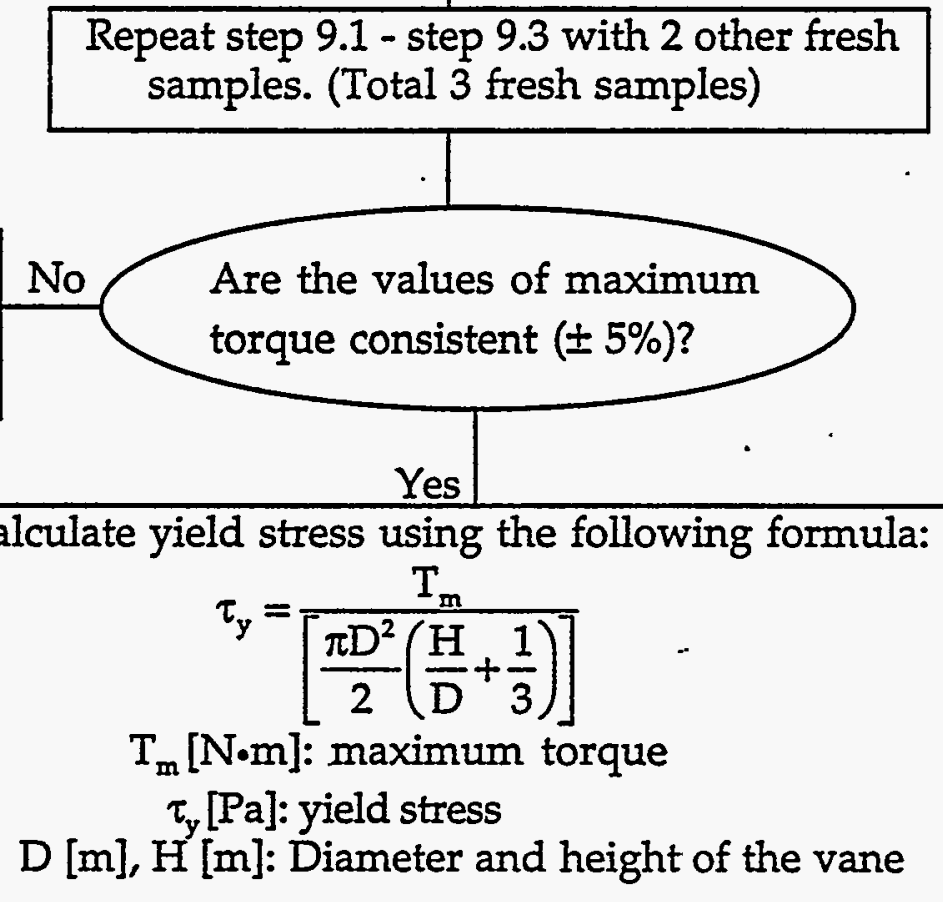




\section{PNL TECHNICAL PROCEDURE}

Procedure No.: ETC-001-001 Revision No.: 0 Effective Date: 5/16/95 Page 23 of 39

C. Steady shear (concentric cylinders)

1. The steady shear viscosity and qualitative thixotropic/rheopectic behavior of slurries can be measured with concentric cylinders (see Figure 12.1C on page 25).

2. Follow procedures in Figure 12.1A (Step A2 through Step A8) for one fresh sample to determine the range of shear rates that may be used to measure steady shear viscosity. ..

3. Check flow curves for Taylor vortices, i.e., a sudden shear stress increase on the flow curve (see Figure 12.1.2 in 12.1A).

- If no increase, go to next step.

- If there is an increase, then estimate shear rate where Taylor vortices are predicted to start, using equations (12.1A.1) and (12.1A.2).

Compare the predicted value and the experimental value for consistency $( \pm 10 \%)$.

- If the values are not consistent, consult with cognizant scientist/engineer before continuing the work.

- If the values are consistent, do not use the shear rate beyond the point where Taylor vortices occur for the following measurement.

4. Measure shear stress, then calculate and plot viscosity as a function of time at a fixed shear rate ( 3 fresh samples total). (Note: use a shear rate at which Taylor vortices did not occur.)

5. Check if the flow curves are repeatable $( \pm 5 \%)$ for three runs.

- If no, consult with cognizant scientist/engineer before continuing the work.

- If yes, go to next step. 


\section{PNL TECHNICAL PROCEDURE}

Procedure No.: ETC-001-001 Revision No.: 0 Effective Date: 5/16/95 Page 24 of 39

6. Obtain steady shear viscosity by averaging the steady state values of the three flow curves. (Note: the value obtained here is without wall slip correction.)

7. Measure the qualitative thixotropic/rheopectic or time-independent behavior of slurries material.

- If the viscosity increases versus time, the behavior is rheopectic. The rate of viscosity versus time (i.e., the slope of the viscosity-time curve) can be used as a measure of rheopexy for $\bar{a}$ fixed shear rate. (Note: this is due to microstructural change in slurries subjected to a constant shearing flow. The particle aggregation rate is faster than that of breakup.)

- If the viscosity decreases versus time, the behavior is thixotropic. The rate of viscosity versus time can be used as an measure of thixotropy for a fixed shear rate. (Note: particle aggregation rate is slower than that of break-up.)

- If the viscosity is constant versus time, the behavior is timeindependent. (Note: particle aggregation rate is close to that of breakup.) 
PNL TECHNICAL PROCEDURE

Procedure No.: ETC-001-001 Revision No.: 0 Effective Date: 5/16/95 Page 25 of 39

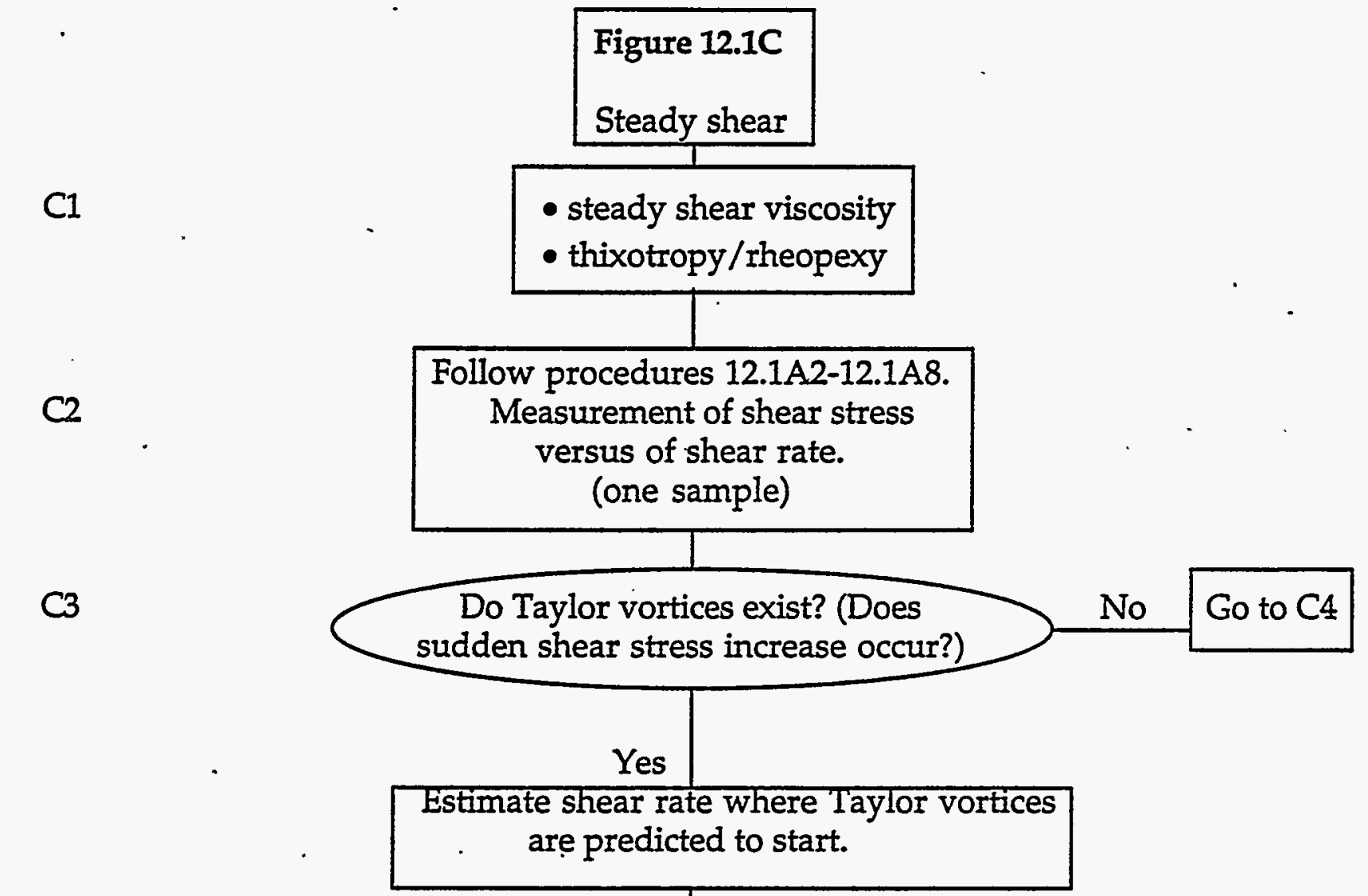

Consult with cognizant scientist /engineer

C4

Measure shear stress, then calculate and plot viscosity at a fixed shear rate as a function of time ( 3 fresh samples total)

Consult with cognizant scientist /engineer

No Compare estimated value and experimental values. Are they consistent $( \pm 10 \%)$ ?

$$
\text { Yes }
$$

Do not use the shear rates beyond the point where Taylor vortices occur.

chen of time 


\section{PNL TECHNICAL PROCEDURE}

Procedure No.: ETC-001-001 Revision No.: 0 Effective Date: 5/16/95 Page 26 of 39

Obtain steady shear viscosity by

C6 averaging the steady state values of the three flow curves.

(Note: the value obtained here is without wall slip correction)

C7. Measure the qualitative thixotropic/rheopectic or time independent behavior of the slurries.

- If the viscosity increases versus time, the behavior is rheopectic. The rate of viscosity versus time (i.e., the slope of the viscosity-time curve) can be used as a measure of rheopexy for a fixed shear rate.

- If the viscosity decreases versus time, the behavior is thixotropic. The rate of viscosity versus time can be used as a measure of thixotropy for a fixed shear rate.

- If the viscosity is constant versus time, the behavior is timeindependent. 


\section{PNL TECHNICAL PROCEDURE}

Procedure No.: ETC-001-001 Revision No.: 0 Effective Date: 5/16/95 Page 27 of 39

D. Sweep rheogram (Parallel plates measurement)

1. The yield stress, plastic viscosity, apparent viscosity, and qualitative thixotropic/rheopectic behavior of slurries are measured with parallel plates (see Figure 12.1D on page 32). Edge effects limit the case of parallel plates for the measurement at very high shear rates since the .sample may flow out of the gap. The benefit of using parallel plate viscometer compared to concentric cylinders is that only small amount of sample is needed for the test. Also, one should note that the shear rate is constant (or flow is simple shear) with concentric-cylinder geometry but varies with position for the parallel-plate geometry. The shear rate used for the parallel plates measurement is the shear at the edge of the plates.

2. Select sensor for measurement. Use Haake $Q 45$ sensor for slurry maximum particle sizes $<1000 \mu \mathrm{m}$, and plastic viscosity $>5 \mathrm{cp}$ and $<10^{9} \mathrm{cp}$. Gap size should be 3 times larger than the maximum particle size.

- If maximum particle size $>1000 \mu \mathrm{m}$, use Haake MV3 sensor.

- If plastic viscosity $<5 \mathrm{cp}$, use Haake MV1 sensor.

- If plastic viscosity $>10^{9} \mathrm{cp}$, use Haake $\mathrm{Q} 20$ or $\mathrm{Q} 30$ sensors.

- If plastic viscosity $<5 \mathrm{cp}$ and maximum particle size $>1000 \mu \mathrm{m}$, methods development is needed.

(Note: the measuring range for a specific MV-type sensor is shown in Figure 12.1D.1)

A trial and error approach may be required to determine which sensor is appropriate for use.

3. Shake or stir the sample to make sure that it has been homogenized. Add sample on the bottom plate. Three samples are to be used.

4. Lower the upper plate so that $\Delta \mathrm{h}$ (the distance between two plates) $=2 \mathrm{~mm}$. 


\section{PNL TECHNICAL PROCEDURE}

Procedure No.: ETC-001-001 Revision No.: 0 Effective Date: 5/16/95 Page 28 of 39

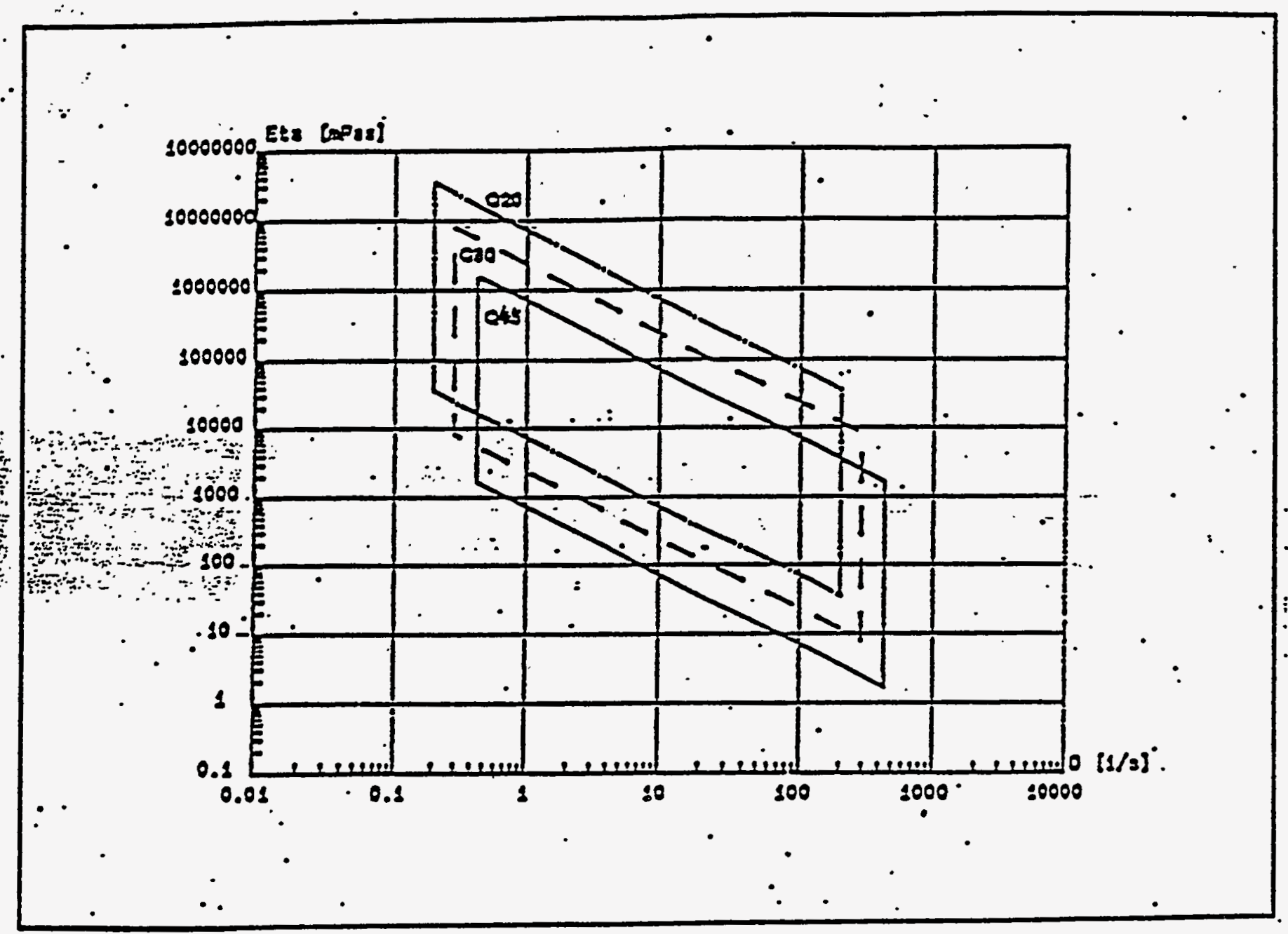

Figure 12.1.D.1 The measuring range for a specific Q-type sensor. 


\section{PNL TECHNICAL PROCEDURE}

Procedure No.: ETC-001-001 Revision No.: 0 Effective Date: 5/16/95 Page 29 of 39

5. The excess sample would flow from the gap into the groove of the bottom plate. Remove excess sample with a suitable syringe. (Note: doing so would allow one to see if the sample is flowing out of the gap during the test)

6: Set sweep time:

$0-218 \mathrm{~s}^{-1}: 2$ minutes, then $218-\theta \mathrm{s}^{-1}: 2$ minutes. (Note: increased shear time for the period of $0-218 \mathrm{~s}^{-1}$ can reduce the thixotropic/rheopectic phenomenon, however, the original material microstructure can also be disturbed during a longer preshear time.) Here, $218 \mathrm{~s}^{-1}$ is the maximum shear rate range for $Q 45$ sensor. Due to the sensitivity of the slurry to shear history, consult with cognizant scientist/engineer if a longer period of shear time is required.

7. Check if sensor size is correct, i.e., if the values of shear stress for shear rate between $0-218 \mathrm{~s}^{-1}$, are in the valid range as shown in Figure 12.1D.1.

- If no, consult with cognizant scientist/engineer for a proper type of sensor.

- If yes, go to next step.

8. Measure shear stress versus shear rate with three fresh samples (use new sample after each measurement). (Note: fresh samples must be loaded for each measurement because of the sensitivity of slurries to the shear history.)

9. Use both upper and lower curves (if thixotropy/rheopexy is observed) for analysis. The upper curve approximates the starting flow in pipe (where the fluid is initially undisturbed), while the lower curve approximates sheared flow in pipe (where the fluid has been deformed as the time progresses).

10. Check if each pair of upper and lower flow curves is consistent (repeatable, . $\pm 5 \%)$ for three runs.

- If flow curves are not consistent, consult with cognizant scientist/engineer before continuing the work.

- If flow curves are consistent, go to next step. 


\section{PNL TECHNICAL PROCEDURE}

Procedure No.: ETC-001-001 Revision No.: 0 Effective Date: 5/16/95 Page 30 of 39

11. Identify if wall slip corrections are required, repeat Steps 3-10 above using different gap sizes (for example, $1 \mathrm{~mm}, 3 \mathrm{~mm}$, and $4 \mathrm{~mm}$ ).

12. Check if wall slip effect exists. (Note: if there is no wall slip, the flow curves from different gap sizes should be the same $[ \pm 5 \%]$ )

- If no, go to next step.

- If yes, correct wall slip and obtain correct flow curve using the following formulas (Yilmazer and Kalyon 1989).

- Obtain the shear rates $\dot{\gamma}_{\mathrm{aR}}\left[\mathrm{s}^{-1}\right]$ from data at different gap sizes $(\mathrm{H})[\mathrm{m}]$ with a specific shear stress $\tau_{\mathrm{R}}[\mathrm{Pa}]$ (recommend minimum of $10 \tau_{\mathrm{R}}$ values).

- Plot $\dot{\gamma}_{\mathrm{aR}}$ versus $1 / \mathrm{H}$ at constant $\tau_{\mathrm{R}} \mathrm{s}$ and obtain straight lines (one straight line for each $\tau_{\mathrm{R}}$ ).

- Calculate $u_{s}\left(\tau_{R}\right)[\mathrm{m} / \mathrm{s}]$ and $\dot{\gamma}_{R}\left(\tau_{R}\right)$ for each straight line with a specific value of $\tau_{\mathrm{m}}$ using formula:

$$
\dot{\gamma}_{\mathrm{aR}}^{\prime}=\dot{\gamma}_{\mathrm{R}}\left(\tau_{\mathrm{R}}\right)+\frac{2 \mathrm{u}_{\mathrm{s}}\left(\tau_{\mathrm{R}}\right)}{\mathrm{H}}
$$

where $\dot{\gamma}_{R}\left(\tau_{R}\right)\left[s^{-1}\right]$ is the extrapolated intercept and is the true shear rate, $2 u_{s}\left(\tau_{R}\right)$ is the slope of the straight line, and $u_{s}\left(\tau_{R}\right)[\mathrm{m} / \mathrm{s}]$ is the slip velocity at the wall.

- Plot out $\tau_{R}$ versus $\dot{\gamma}_{R}\left(\tau_{R}\right)$

13. Use curve-fitting software on final (or corrected) flow curve. 


\section{PNL TECHNICAL PROCEDURE}

Procedure No.: ETC-001-001 Revision No.: 0 Effective Date: 5/16/95 Page 31 of 39

14. Select best model based on regression for non-Newtonian Fluid (Bingham, H. Bulkley, Casson, etc.). If fluid is Newtonian, $\tau=\eta \dot{\gamma}$ where $\tau[\mathrm{Pa}]$ is the shear stress, $\eta[\mathrm{Pa} \cdot \mathrm{s}]$ the Newtonian viscosity, and $\dot{\gamma}\left[s^{-1}\right]$ the shear rate.

- Bingham Model: $\tau=\tau_{0}^{\mathrm{B}}+\eta_{\mathrm{p}} \dot{\gamma}$ where $\tau$ is the shear stress, $\tau_{0}^{\mathrm{B}}$ the Bingham yield stress, $\eta_{\mathrm{p}}$ the plastic viscosity, and $\dot{\gamma}$ the shear rate.

- Herschel-Bulkley Model: $\tau=\tau_{0}^{\mathrm{H}}+k \dot{\gamma}^{\mathrm{n}}$ where $\tau$ is the shear stress, $\tau_{0}^{\mathrm{H}}$ the yield stress, $k$ and $n$ the parameters, and $\dot{\gamma}$ the shear rate.

- Casson Model: $\tau^{\frac{1}{2}}=\left(\tau_{0}^{c}\right)^{\frac{1}{2}}+\left(\eta_{c} \dot{\gamma}\right)^{\frac{1}{2}}$ where $\tau$ is the shear stress, $\tau_{0}^{c}$ the Casson yield stress, $\eta_{c}$ the consistency parameter, and $\dot{\gamma}$ the shear rate.

(Note: if the material has no yield stress, $\tau_{0}^{\mathrm{B}}, \tau_{0}^{\mathrm{H}}$, and $\tau_{0}^{\mathrm{c}}$ should be zero.)

15. Obtain the following parameters from each model: (This is for the pressure drop estimate in pipe flow, see Section 12.2 on page 35)

- Bingham model: the Bingham yield stress, $\tau_{0}^{\mathrm{B}}$, and the plastic viscosity, $\eta_{\mathrm{p}^{*}}$

- Herschel-Bulkley Model: the yield stress, $\tau_{0}^{\mathrm{H}}$, and the parameters, $\mathrm{k}$ and n.

- Casson Model: the Casson yield stress, $\tau_{0}^{c}$, and the consistency parameter, $\eta_{c^{\circ}}$

16. Determine apparent viscosity by dividing the corrected shear stress by a specific shear rate. For example, the apparent viscosity for a shear rate $\dot{\gamma}$ with shear stress $\tau$ is $\tau / \dot{\gamma}$.

17. Determine thixotropic/rheopectic behavior by measuring the area between the "up" and "down" curves of the corrected rheogram (Mewis 1979). 


\section{PNL TECHNICAL PROCEDURE}

Procedure No.: ETC-001-001 Revision No.: 0 Effective Date: 5/16/95 Page 32 of 39

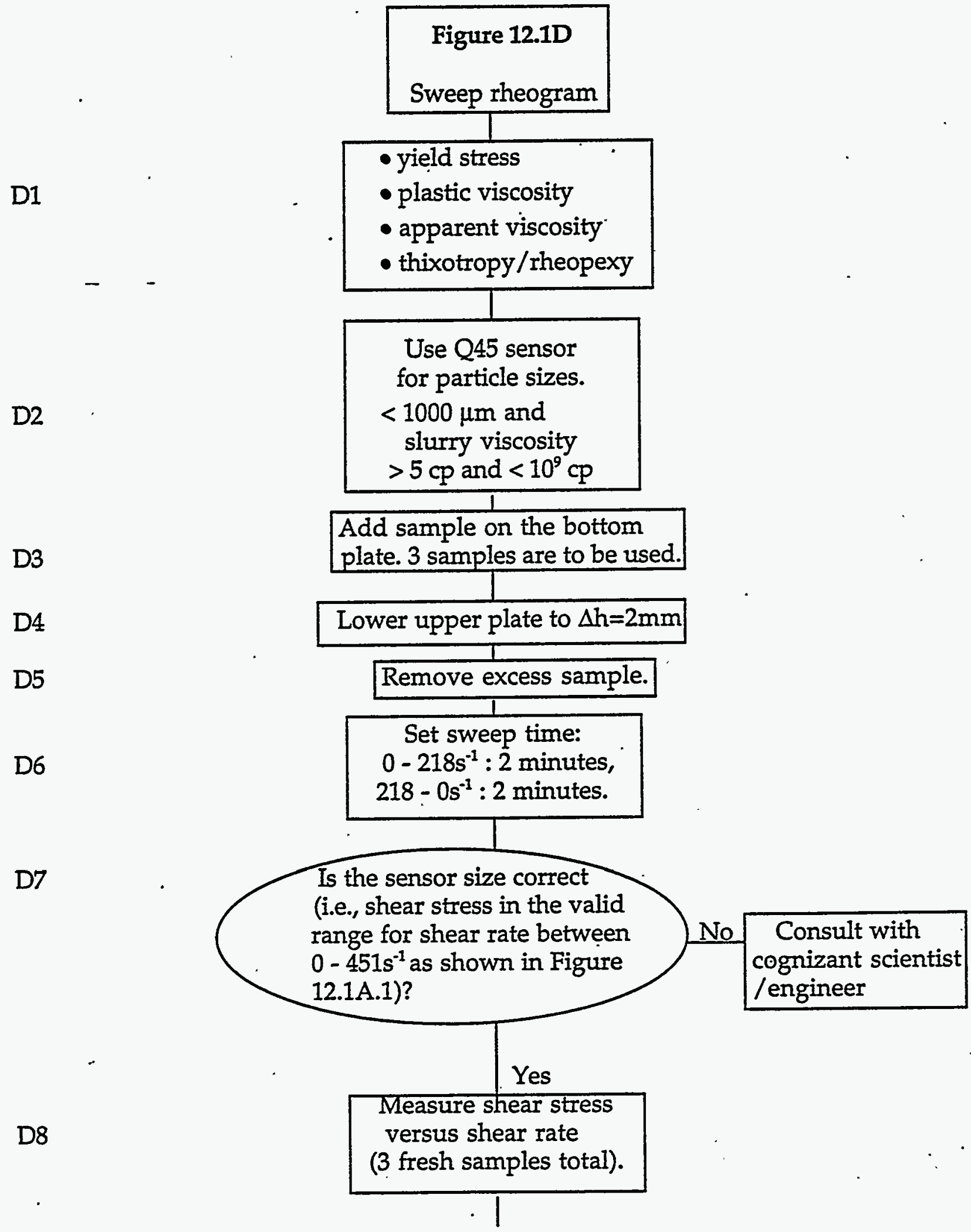


PNL TECHNICAL PROCEDURE

Procedure No.: ETC-001-001 Revision No.: 0 Effective Date: 5/16/95 Page 33 of 39

D9

Use both upper and lower curves

(which approximate the undisturbed and sheared flows in pipe) for analysis.

\begin{tabular}{|l|}
\hline $\begin{array}{l}\text { Consult with } \\
\text { cognizant scientist } \\
\text { /engineer }\end{array}$ \\
\hline
\end{tabular}

No

Are flow curves

D10

D11

Repeat Steps D3-D10 with different gap sizes ( $1 \mathrm{~mm}, 3 \mathrm{~mm}$, and $4 \mathrm{~mm}$ ). This is for the wall-slip correction.

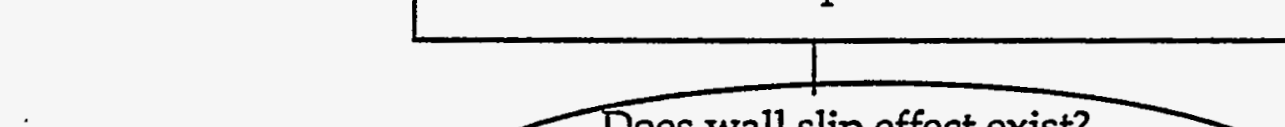

No Does wall slip effect exist?

(If no wall slip, curves from different

D12

gap sizes should be the same $[ \pm 5 \%]$.)

Yes

Obtain the shear rates $\dot{\gamma}_{\mathrm{aR}}^{\prime}$ from data at different gap sizes $(\mathrm{H})$ with a

specific shear stress $\tau_{R^{*}}\left(10 \tau_{R}\right.$ values).

Plot $\dot{\gamma}_{\text {aR }}^{\prime}$ versus $1 / \mathrm{H}$ at constant $\tau_{\mathrm{R}}$ s and obtain straight lines (one straight line for each $\tau_{R}$ ).

Calculate $u_{s}\left(\tau_{R}\right)$ and $\dot{\gamma}_{R}\left(\tau_{R}\right)$ for each straight line with a specific value of $\tau_{\mathrm{m}}$ using formula:

$$
\dot{\gamma}_{\mathrm{aR}}^{\prime}=\dot{\gamma}_{\mathrm{R}}\left(\tau_{\mathrm{R}}\right)+\frac{2 \mathrm{u}_{\mathrm{s}}\left(\tau_{\mathrm{R}}\right)}{\mathrm{H}}
$$

where $\dot{\gamma}_{R}\left(\tau_{R}\right)$ is the extrapolated intercept and is the true shear rate, $2 u_{s}\left(\tau_{R}\right)$ is the slope of the straight line, and $u_{s}$ $\left(\tau_{R}\right)$ is the slip velocity at the wall. 
PNL TECHNICAL PROCEDURE

Procedure No.: ETC-001-001 Revision No.: 0 Effective Date: 5/16/95 Page 34 of 39

D13

Use curve-fitting software on flow curve.

D14

Select best model based on regression (Bingham, H.Bulkley, Casson, etc.).

D15

Obtain the following parameters from each model:

- Bingham Model: the Bingham yield stress, $\tau_{0}^{\mathrm{B}}$, and the plastic viscosity, $\eta_{\mathrm{p}}$.

- Herschel-Bulkley Model: the yield stress, $\tau_{0}^{\mathrm{H}}$, and the parameters, $k$ and $n$.

- Casson Model: the Casson yield stress, $\tau_{0}^{\mathrm{c}}$ and the consistency parameter, $\eta_{c}$. measuring the slope of the corrected shear stress versus shear rate curve for a specific shear rate. between the "up" and "down" corrected curves. 


\section{PNL TECHNICAL PROCEDURE}

Procedure No.: ETC-001-001 Revision No.: 0 Effective Date: 5/16/95 Page 35 of 39

\subsection{Applications}

A. Pressure drop $(\Delta \mathrm{P})$ estimation for pipe flow

The procedure described in this section has been commonly used for the estimate of pressure drop in pipe flow (Bird et al. 1960; Shook and Roco 1991). However, the estimated results have not been verified with the experimental pipe flow data. The person who would like to apply the estimated results obtained from this section should consult with the cognizant. scientist/engineer.

1. Follow procedures in 12.1A (Steps 2 through 7 and Steps 9 through 14) or 12.1D (Steps 2 through 7 and Steps 9 through 13). Step 8 in both $12.1 \mathrm{~A}$ and 12.1D should be changed as follows: Take the data with decreasing shear rate and treat increasing shear part as a preshear (see Figure 12.2A on page 38).

2. Collect pipe flow engineering data, for example, pipe length $L[\mathrm{~m}]$, pipe diameter $\mathrm{D}[\mathrm{m}]$, and average velocity $\mathrm{V}[\mathrm{m} / \mathrm{s}]$.

3. Report parameters from the rheological models according to Step 16 in 12.1 A or Step 15 in 12.1D.

- Bingham Model: the Bingham yield stress, $\tau_{0}^{\mathrm{B}}[\mathrm{Pa}]$, and the plastic viscosity, $\eta_{\mathrm{p}}[$ Pa.s].

- Herschel-Bulkley Model: the yield stress, $\tau_{0}^{\mathrm{H}}[\mathrm{Pa}]$, and the parameters, $\mathrm{k}$ and $n$.

- Casson Model: the Casson yield stress, $\tau_{0}^{c}[\mathrm{~Pa}]$, and the consistency parameter, $\eta_{c}[$ Pa.s].

4. Calculate pressure drop $(\Delta P)[\mathrm{Pa}]$ based on selected model (consult with cognizant scientist/engineer regarding to which model should be used):

The following formulas are valid only for laminar pipe flow (i.e., the Reynolds number is less than 2100). If the Reynolds number is greater than 2100 (i.e., the flow is turbulent), method development is needed. 
Procedure No.: ETC-001-001 Revision No.: 0 Effective Date: 5/16/95 Page 36 of 39

The formula for Reynolds number is:

$$
N_{R E}=\frac{D V \rho}{\mu_{e}} \leq 2100
$$

where $\rho\left[\mathrm{g} / \mathrm{m}^{3}\right]$ is the fluid density, $\mathrm{D}[\mathrm{m}]$ the pipe diameter, $\mathrm{V}[\mathrm{m} / \mathrm{s}]$ the average flow velocity, and $\mu_{\mathrm{e}}[\mathrm{Pa} \cdot \mathrm{s}]$ the effective viscosity of slurry suspensions.

- Bingham Model:

The effective viscosity can be expressed as

$$
\mu_{e}=\frac{\tau_{0}^{B} \mathrm{D}}{6 \mathrm{~V}}+\eta_{p}
$$

where $\tau_{0}^{\mathrm{B}}[\mathrm{Pa}]$ is the Bingham yield stress and $\eta_{\mathrm{p}}[\mathrm{Pa} \cdot \mathrm{s}]$ is the plastic viscosity.

$\Delta \mathrm{p} / \mathrm{L}$ can be calculated by using the formula (Bird et al. 1960):

$$
\frac{\Delta \mathrm{p}}{\mathrm{L}}=\frac{32 \eta_{\mathrm{p}} \mathrm{V}}{\mathrm{g}_{\mathrm{c}} \mathrm{D}^{2}}+\frac{16 \tau_{0}^{\mathrm{B}}}{3 \mathrm{D}}
$$

where $L[\mathrm{~m}]$ the pipe length and $\Delta \mathrm{p}[\mathrm{Pa}]$ is the pressure drop. Because $\mathrm{D}[\mathrm{m}]$ and $\mathrm{V}[\mathrm{m}]$ are available, one can estimate $\Delta \mathrm{p} / \mathrm{L}$ for the pipe flow.

- Herschel-Bulkley Model

Calculating effective viscosity of Herschel-Bulkley Model is complicated because the equation is complex (12.2.4). Therefore, no formula is available in the literature. A practical way to estimate the effective viscosity for the Herschel-Bulkley fluid flowing in pipe is to fit the original corrected rheogram from 12.1A12 with the Bingham.Model. Then use the obtained Bingham yield stress and plastic viscosity with equation (12.2.2) to calculate the effective viscosity and estimate the Reynolds number using equation (12.2.1). 


\section{PNL TECHNICAL PROCEDURE}

Procedure No.: ETC-001-001 Revision No.: 0 Effective Date: 5/16/95 Page 37 of 39

$\Delta \mathrm{p} / \mathrm{L}$ can be calculated by the formula (Shook and Roco 1991):

$$
\frac{8 V}{D}=4\left(\frac{\tau_{w}}{k}\right)^{\frac{1}{n}}\left[\left(\frac{\xi^{2}}{a}\right)(1-\xi)^{a}+\left(\frac{2 \xi}{b}\right)(1-\xi)^{b}+\left(\frac{1}{c}\right)(1-\xi)^{c}\right]
$$

where $\tau_{w}=\frac{D \Delta p}{4 L}, \xi=\frac{\tau_{0}^{B}}{\tau_{w}}, a=1+\left(\frac{1}{n}\right), b=2+\left(\frac{1}{n}\right), c=3+\left(\frac{1}{n}\right)$

Here, $\tau_{0}^{\mathrm{H}}[\mathrm{Pa}]$ is the yield stress and $\mathrm{k}$ and $\mathrm{n}$ are parameters from the HerschelBulkley Model. As D [m] and V [m/s] are known, one can estimate $\Delta \mathrm{p} / \mathrm{L}$ for the pipe flow.

- Casson Model

The effect viscosity can be expressed as:

$$
\mu_{e}=\frac{\tau_{0}^{c} D}{6 V}+\eta_{c}+\frac{32 \tau_{0}^{c} D}{49 V}
$$

where $\tau_{0}^{c}[\mathrm{~Pa}]$ is the Casson yield stress and $\eta_{c}[\mathrm{~Pa} \cdot \mathrm{s}]$ is the consistency parameter.

$\Delta \mathrm{p} / \mathrm{L}$ can be calculated by using the formula (Shook and Roco 1991):

$$
\frac{8 \mathrm{~V}}{\mathrm{D}}=\left[1-\left(\frac{16}{7}\right)\left(\frac{\tau_{0}^{\mathrm{c}}}{\tau_{\mathrm{w}}}\right)^{\frac{1}{2}}+\left(\frac{3}{4}\right)\left(\frac{\tau_{0}^{\mathrm{c}}}{\tau_{\mathrm{w}}}\right)-\left(\frac{1}{21}\right)\left(\frac{\tau_{0}^{\mathrm{c}}}{\tau_{\mathrm{w}}}\right)^{4}\right]\left(\frac{\tau_{\mathrm{w}}}{\eta_{\mathrm{c}}}\right)
$$

where $\tau_{\mathrm{w}}=\frac{\mathrm{D} \Delta \mathrm{p}}{4 \mathrm{~L}}$. Because $\mathrm{D}[\mathrm{m}]$ and $\mathrm{V}[\mathrm{m} / \mathrm{s}]$ are known, one can estimate $\Delta \mathrm{p} / \mathrm{L}$ for the pipe flow. 
PNL TECHNICAL PROCEDURE

Procedure No.: ETC-001-001 Revision No.: 0 Effective Date: 5/16/95 Page.38 of 39

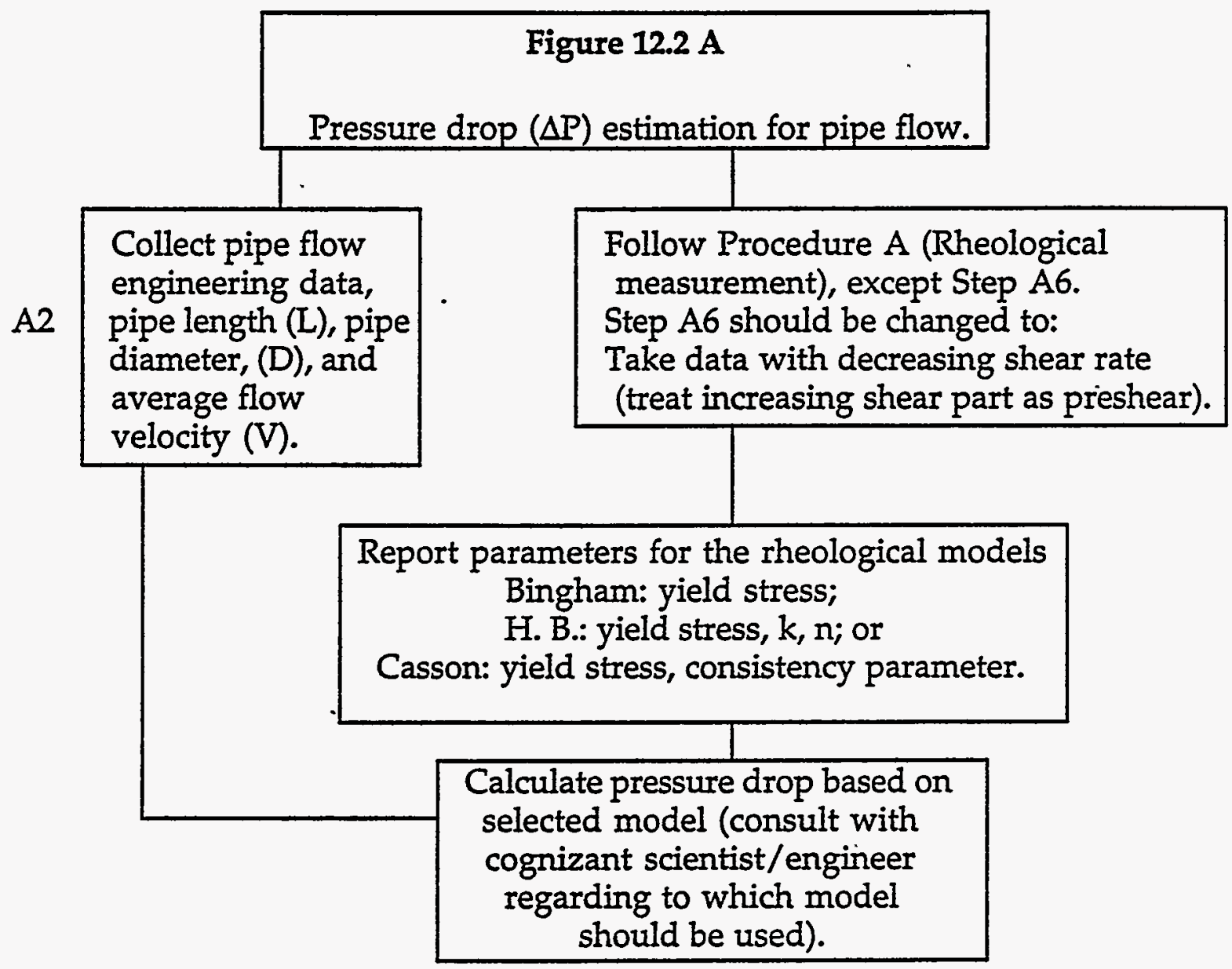




\section{PNL TECHNICAL PROCEDURE}

Procedure No.: ETC-001-001 Revision No:: 0 Effective Date: 5/16/95 Page 39 of 39

\subsection{SOURCE REOUTREMENTS}

Technical Procedure No: WTC-006-4: Physical Properties Measurement. (This procedure is for measurement of density, total weight percent solids, gram waste oxide per liter, yield stress, and plastic viscosity.)

Bird, R. B., W. E. Stewart, and E. N. Lightfoot. 1960. Transport Phenomena.

Dzuy, N. Q. and D. V. Boger. 1983. J. Rheol. 27, 321.

Haake Instruction Manual : Retovisco RV20 Measuring System M.

Haake Viscometers: Introduction to Practical Viscometry.

Haake Viscometers: Optimization of Rotovisco Tests.

Kiljanski, T. 1989. Rheol. Acta 28, 61.

Mewis, J. 1979. J. Non-Newtonian Fluid Mechanics 6, 1.

Shook, C. A., and M. C. Roco. 1991. Slurry Flow : Principles and Practices.

Taylor, G. I. 1923. Phil. Trans. Roy. Soc. A. 223, 289.

Yilmazer, U. and D. M. Kalyon. 1989. J. Rheol. 33, 1198. 